\title{
ELETRODOS ARTESANAIS PARA VOLTAMETRIA
}

\author{
Reinaldo Carvalho Silva \\ Escola Técnica Federal de Santa Catarina - Av. Mauro Ramos, 950 - 88020-300 - Florianópolis - SC \\ Ivan Gonçalves de Souza \\ Depto. de Química - Universidade Federal de Santa Catarina - 88040-900 - Florianópolis - SC
}

Recebido em 19/3/97; aceito em 3/12/97

\begin{abstract}
HOMEMADE ELECTRODES FOR VOLTAMMETRY. This paper describes the construction and performance of homemade electrodes for voltammetric purpose using cheap materials, like pipette tips and asbestos fiber. A good cost-to-benefit relation makes this devices specially designed for student use, expecting to improve the broadcasting of electroanalytical methods in Brazilian schools.
\end{abstract}

Keywords: reference electrode; working electrode; auxiliary electrode.

\section{INTRODUÇÃO}

Um questionário preenchido por professores participantes do Curso de Aperfeiçoamento em Análise Instrumental para Docentes Latino Americanos, realizado em 1991 na Escola Técnica Federal de Química do Rio de Janeiro, mostrou que em nenhuma das escolas técnicas com curso de química no Brasil, Paraguai e Equador se ensinava a voltametria nas atividades de química analítica. Ainda hoje persiste esta realidade, apenas um pouco atenuada nos cursos de graduação, embora a eletroanalítica venha representando já uns $14 \%$ das publicações brasileiras em química analítica ${ }^{1}$, provavelmente como resultado de grande produtividade de poucos grupos. Em parte, esta situação deve-se ao elevado custo de potenciostatos e eletrodos, tornando-os inacessíveis para o ensino em algumas escolas técnicas e universidades. Sem o auxílio destes materiais, ficam prejudicados o domínio técnico e, por falta de apoio concreto, também o domínio teórico. Instrumentos não comerciais de baixo custo aparecem em nossa literatura técnica ${ }^{2-9}$. Todavia, a confecção de eletrodos artesanais não tem recebido o devido destaque, razão pela qual procuramos desenvolvê-los, descrevendo aqui o que poderá ser de ajuda a outros que venham a se encontrar na mesma situação. Superada a dificuldade de ordem prática, interessantes estudos iniciais poderão ser realizados ${ }^{10}$. A própria feitura dos eletrodos pelos alunos representa um ganho pedagógico pelo "desvelar das caixas-pretas".

\section{EXPERIMENTAL}

O amianto usado foi para filtração, de fibra média, da Reagen. As ponteiras de pipetador foram de 2 tamanhos: a BRAND amarela de $10-100 \mu \mathrm{L}$ e a KACIL branca de $10-250 \mu \mathrm{L}$ (Camelo \& Cia). O mercúrio para eletrodo de calomelano foi grau analítico mas deverá ser o mais puro que se puder dispor. O mesmo é válido para os fios de prata e platina. O grafite precisa ser especial para finalidade eletroquímica. Nós usamos o grafite SYNTH sem qualquer especificação, com resultados insatisfatórios devido à alta corrente capacitiva e alta queda ôhmica dos eletrodos de grafite. Os tubos de vidro de todas as preparações referem-se a vidro neutro de fácil amolecimento por calor, com diâmetros, interno de $2,5 \mathrm{~mm}$ e externo de $4 \mathrm{~mm}$. O fio de platina, sempre que citado, tem 0,5 a $1,0 \mathrm{~mm}$ de diâmetro. $\mathrm{O}$ fio de cobre em todos os eletrodos foi fio elétrico residencial com diâmetro de $1 \mathrm{~mm}$, do qual se retirou a capa isolante. A resina epoxi foi ARALDITE normal, só sendo usado o tubo de adesivo (o HF é o agente de reticulação). Fita de PTFE (teflon) foi fita veda-juntas com 8-10 $\mathrm{mm}$ de largura. A seringa de vacina foi PLASTIPAK B-D de $1 \mathrm{~mL}$ (descartável) da qual só não foi aproveitada a parte de metal da agulha. Ferroceno P.A. foi purificado por sublimação. A acetonitrila foi grau espectroscópio, seca em peneira molecular de 4 angstron. A água foi deionizada em sistema MILLI-Q DA FIRMA MILIPOR (condutividade de $0,1 \mu \mathrm{S} / \mathrm{cm}$ ). Todas as demais substâncias foram grau analítico e utilizadas tal como recebidas. A solda foi em fio de $1 \mathrm{~mm}$ de diâmetro, de estanho e chumbo (63/37), contendo decapante, usada para montagem de circuitos eletrônicos. A lupa ideal é uma binocular, usada pelos biólogos, no aumento de umas $20 \mathrm{x}$, mas uma de relojoeiro já é satisfatória. $\mathrm{O}$ maçarico foi à gás butano, sem ar comprimido.

As medidas de potencial dos eletrodos foram feitas submergindo-os em $\mathrm{KCl}$ saturado e ligando-os a um medidor de $\mathrm{pH}$, lendo-se na escala de milivolt vs. ECS. As medidas de resistência de junção foram feitas mergulhando o eletrodo pronto em $\mathrm{KCl}$ saturado e, usando um eletrodo de prata, mediu-se, com multímetro, a corrente gerada por fonte de corrente alternada de 50-60 HZ, calculando-se a resistência pela lei de $\mathrm{Ohm}^{11}$. A velocidade de difusão de íons cloreto através da junção, mediu-se por titulação (método de Mhor), após deixarse o eletrodo com a ponta em água deionizada por 72 horas. A vazão de eletrólito através da junção, foi feita deixando-se em ambiente úmido a ponteira com junção completamente cheia de $\mathrm{KCl}$ saturado (coluna de água de $40 \mathrm{~mm}$ ). Após 66 horas, completou-se o nível original com pipeta graduada, medindose o volume. Todas as medidas voltamétricas foram realizadas no potenciostato da MICROQUÍMICA IND. E COM. LTDA com controle e aquisição de dados por microcomputador 386 , dotado de placa conversora do mesmo fabricante.

\section{ELETRODOS DE REFERÊNCIA}

A junção e o corpo destes eletrodos são constituídos de fibra de amianto comprimida na ponta de ponteira de pipetador de 10-100 $\mu \mathrm{L}$. Cortam-se $4 \mathrm{~mm}$ da ponta da ponteira, deixando-se uma abertura de, aproximadamente, $0,8 \mathrm{~mm}$ de diâmetro. Coloca-se uma porção de amianto tal que, comprimida, venha a medir ente 5 e $10 \mathrm{~mm}$ de altura. Percute-se a ponteira para acomodar a fibra na sua parte mais fina e aperta-se o amianto com uma ferramenta mantendo a ponteira na vertical com a ponta sobre uma superfície plana e limpa. Com um martelinho, golpeia-se a ferramenta sobre a fibra até que esta resulte bem compactada. $\mathrm{O}$ grande mérito desta junção é que, simples e barata, pode ser descartada em caso de suspeita de colmatação ou contaminação (Amianto é nocivo. Evite-se contato ou inalação). 
O eletrodo de calomelano é preparado, para trabalhos em meio aquoso, baseando-se nas instruções do livro de Adams ${ }^{12}$. Mistura-se cloreto mercuroso em pó com mercúrio, em geral escrupulosamente limpo, até que fique cinza brilhante. Adicionam-se gotas de $\mathrm{KCl}$ saturado até que se obtenha uma pasta homogênea. Um tubo de vidro com $23 \mathrm{~mm}$ de comprimento é soldado a um fio de platina com $10-15 \mathrm{~mm}$ de comprimento, de modo que fiquem uns $5 \mathrm{~mm}$ para fora do tubo. Ao ser retirado do calor do maçarico, esfria-se o tubo em dessecador. Com a pasta de calomelano- $\mathrm{Hg}$, enche-se o interior do tubo, deixando-se 1-2 mm que serão preenchidos com fibra de amianto.

Enche-se o corpo do eletrodo com solução saturada de $\mathrm{KCl}$, valendo-se da seringa de $1 \mathrm{~mL}$ com uma ponteira de pipetador no lugar da agulha, ou de um conta-gotas de ponta longa e fina. Cuide-se para que não hajam bolhas de ar. Finalmente, acoplamse ponteira e tubo de vidro, evitando-se a formação de bolhas de ar. Este acoplamento é conseguido valendo-se de um pedaço de ponteira de 10-250 $\mu \mathrm{L}$, conforme ilustra a figura 1 .

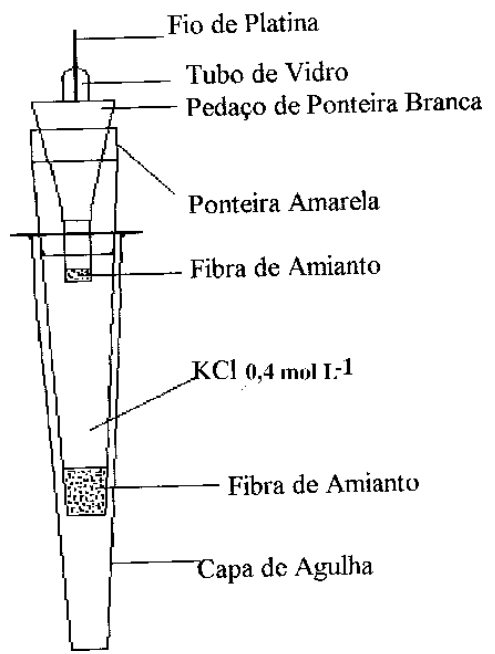

Figura 1. Eletrodo de referência de calomelano.

Ao final de um dia de trabalho esvazia-se o eletrodo e recarrega-se com nova solução de $\mathrm{KCl}$. Estando fora de uso, é conveniente deixar-se o eletrodo com a ponta encaixada na capa da agulha da seringa contendo solução de $\mathrm{KCl}$ a $0,4 \mathrm{molL}^{-1}$. Periodicamente, devem ser feitos testes de desempenho com este eletrodo, tal como indica Galster ${ }^{11}$.

Em havendo necessidade de evitar os íons cloreto que migram pela junção, deve-se acoplar uma segunda junção, construída tal como a primeira, contendo eletrólito inerte, como $\mathrm{KNO}_{3}$. Para isso é necessário um pedaço de ponteira de 10$250 \mu \mathrm{L}$ adaptado à ponta da primeira junção.

Estudamos para este eletrodo o valor de potencial de eletrodo, a resistência da junção, a velocidade de difusão de íons cloreto pela junção do eletrodo pronto e a vazão de eletrólito pela junção. A tabela 1 mostra os resultados obtidos.

Tabela 1. Características do eletrodo de calomelano artesanal.

\begin{tabular}{lcc}
\hline Características & junção simples & junção dupla \\
\hline $\begin{array}{l}\text { Potencial X ECS } \\
\text { comercial/mV }\end{array}$ & $0,1-2$ & $0,1-2$ \\
$\begin{array}{l}\text { Resistência da } \\
\text { junção/k } \Omega\end{array}$ & $1,3-1,9$ & $2,6-3,8$ \\
$\begin{array}{l}\text { Velocidade de difusão } \\
\text { de Cl-/ } \mu \text { mol h }\end{array}$ & 1,5 & 0,2 \\
$\begin{array}{l}\text { Vazão de } \\
\text { eletrólito/ } \mu \mathrm{L} \mathrm{h}^{-1}\end{array}$ & 1,4 & - \\
\hline
\end{tabular}

Pode-se preparar também o eletrodo de $\mathrm{Ag} / \mathrm{AgCl}$ seguindo indicações de Sawyer e Roberts ${ }^{13}$. Todavia, percebemos que tal eletrodo exige sempre a dupla junção para evitar o aparecimento de picos voltamétricos devido à prata que migra através da junção como $\left[\mathrm{AgCl}_{2}\right]^{-}$.

Para trabalhos em meio não-aquoso descrevemos o eletrodo de $\mathrm{Ag} / \mathrm{Ag}^{+}$0,01 $\mathrm{molL}^{-1}$ indicado por Sawyer e Roberts ${ }^{13}$ : Um fio de prata é cortado com comprimento de $25 \mathrm{~mm}$, sua ponta enrolada na ponta de fio de cobre com $20 \mathrm{~mm}$ de comprimento e alí soldada em seguida. Escolhe-se uma agulha de injeção descartável, cujo diâmetro coincida com o do fio de prata e extrai-se a agulha de seu suporte com um alicate. No orifício resultante, introduz-se o fio de prata, deixando-se o terminal de cobre para a parte mais larga do suporte da agulha e acomodando a parte da solda dentro da cavidade. Preenche-se esta cavidade com epoxi-HF ${ }^{14}$ ( 1 gota de $\mathrm{HF} 40 \%+0,5 \mathrm{~g}$ de resina epoxi) e espera-se uma noite a temperatura ambiente, completando a reticulação por mais $2 \mathrm{~h}$ a $60^{\circ} \mathrm{C}$ (HF é nocivo. Trabalhar em capela!). O fio de prata é então polido por lixa 600 , decapado por $\mathrm{HNO}_{3}$ 1+1, lavado em acetona e seco ao ar. Prepara-se $\mathrm{AgNO}_{3}$ a $0,01 \mathrm{~mol} / \mathrm{L}$ em acetonitrila e carrega-se o corpo do eletrodo (preparado tal como para o ECS) com esta solução. Acopla-se com firmeza o fio de prata ao corpo do eletrodo, segurando-se pelo suporte do fio. Recomenda-se uma segunda junção, contendo o eletrólito de suporte ${ }^{13}$. Estando fora de uso, manter dentro de uma capa de agulha contendo o eletrólito (Figura 2). Este eletrodo mostrou-se adequado para voltametria de complexos em $\mathrm{CH}_{3} \mathrm{CN}$, usando como padrão interno o par ferroceno/ferrocínio, recomendado por Gagné ${ }^{15}$.



Figura 2. Eletrodo de referência de $\mathrm{Ag} / \mathrm{Ag}^{+}$para trabalhos em meio não aquoso.

Em 10 varreduras de potencial a $50 \mathrm{mVs}^{-1}$, realizadas ao longo de $5 \mathrm{~h}$ de trabalho, usando o eletrodo $\mathrm{Ag} / \mathrm{Ag}^{+}$preparado como referência, disco de platina como eletrodo de trabalho e fio de platina como contra-eletrodo, obtivemos, para o ferroceno $10^{-3}$ molL $^{-1}$ em acetonitrila, $E_{1 / 2}$ (médio) $=54 \mathrm{mV}$ com desvio padrão de 2,0\%. O eletrólito de suporte foi o hexafluorfosfato de tetrabutilamônio a $0,1 \mathrm{molL}^{-1}$. Sendo $400 \mathrm{mV}$ o $\mathrm{E}_{1 / 2}$ do ferroceno ${ }^{15}$, temos para $\mathrm{Ag} / \mathrm{Ag}^{+}$a $0,01 \mathrm{molL}^{-1} \mathrm{em}$ acetonitrila: $346 \mathrm{mV}$.

\section{ELETRODO AUXILIAR}

Privilegiando a compactação, o melhor eletrodo seria simplesmente um fio de platina que, projetando-se para fora da célula, conecta-se ao potenciostato. Todavia, a parte não imersa não necessita ser de $\mathrm{Pt}$, podendo ser construídos dois eletrodos auxiliares com um pedaço de fio de platina de 50mm: Corta-se o tubo de vidro com $50 \mathrm{~mm}$ de comprimento e solda-se o fio de 
platina em uma de suas pontas, valendo-se de um maçarico e permitindo que $10 \mathrm{~mm}$ do fio fique para o interior do tubo. Esfria-se e introduz-se no interior do tubo um pedaço de $60 \mathrm{~mm}$ de fio de cobre bem limpo (usar $\mathrm{HNO}_{3} 1+1$ e lavar com acetona secando-se ao ar), fazendo com que se projete uns $10 \mathrm{~mm}$ para fora dele. Introduz-se também pequenos pedaços de solda junto com o cobre, dentro do tubo. Mantendo a posição vertical, aquece-se rapidamente ao maçarico, apenas para fundir a solda, unindo a platina ao cobre. Dá-se o acabamento final com fita de teflon, fechando a parte superior do eletrodo. Para maior compactação, pode-se enrolar a ponta de platina formando uma espiral (Figura 3). A fim de permitir sua fixação na célula voltamétrica, adapta-se um pedaço de ponteira de $10-250 \mu \mathrm{L}$ ao corpo deste eletrodo.

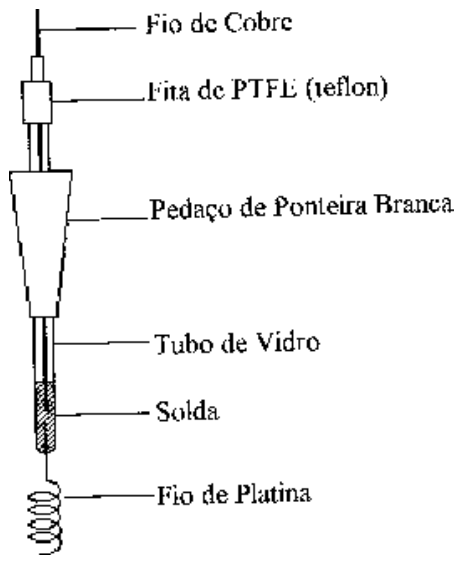

Figura 3. Eletrodo auxiliar de platina.

\section{ELETRODO DISCO DE PLATINA}

Com um pedaço de apenas $6 \mathrm{~mm}$ de fio de platina pode-se construir um eletrodo tipo disco com corpo de vidro.Para tanto, estira-se o tubo de vidro na chama do maçarico de forma a produzir uma ponta. Corta-se o tubo no comprimento total de uns $50 \mathrm{~mm}$ e, aquecendo a ponta afilada dá-se-lhe espessura evitando, porém, que venha a fechar, impedindo a passagem do fio de platina. Fora da chama, adapta-se o fio de platina, de forma que fique apenas ligeiramente para fora da ponta afilada. Na chama oxidante do maçarico, aquece-se a ponta afilada imprimindo um movimento de rotação ao tubo de vidro, retirando-se $\operatorname{logo}$ em seguida da região muito aquecida. É preciso examinar com uma lupa a junção vidroplatina: se aí houver bolhas será impossível preparar o eletrodo, sendo necessário quebrar o vidro, recuperar o fio de platina e recomeçar. Estas bolhas são difíceis de evitar, mas é possível obter resultado satisfatório usando vidro neutro (de baixo "ponto de fusão"), chama bem quente, platina bem limpa e operação rápida, evitando sobreaquecimento do metal. Ao retirar o calor da chama, fazê-lo aos poucos a fim de evitar trincas no vidro, que também inutilizam o eletrodo. Esfriada completamente, lixa-se a ponta de platina até eliminá-la por completo. Prossegue-se desgastando a ponta do eletrodo com uma lixa 400 molhada, até que haja uma superfície plana em redor do disco de platina. Em seqüência, usa-se lixa 600, 1200 e alumina até que vidro e platina estejam espelhados ao exame com uma lupa. É vital que sejam removidas todas as partículas de um abrasivo antes que se passe para outro mais fino. Ao final, deixar somente a ponta do eletrodo por 5 minutos em água deionizada no ultra-som. Adapta-se um fio de cobre exatamente como foi descrito para o eletrodo auxiliar. Havendo necessidade, maiores orientações sobre trabalhos em vidro podem ser encontradas em Barbour ${ }^{16}$. Adapta-se, por fim, um pedaço de ponteira tal como no eletrodo auxiliar.
Um eletrodo assim preparado forneceu o voltamograma cíclico de hexacianoferrato de potássio apresentado na figura 4 . Um polimento mais cuidadoso e soluções melhor desaeradas produzem um voltamograma mais próximo do ideal.



Figura 4. Voltamograma cíclico de uma solução $6 \times 10^{-3} \mathrm{~mol} \mathrm{L^{-1 }}$ de velocidade de varredura de $50 \mathrm{mVs}^{-1}$. Eletrólito de suporte $\mathrm{KNO}_{3}(1$ molL $\left.^{-1}\right)$. Eletrodo de disco de platina.

\section{ELETRODO DE EPOXI GRAFITADA}

Este eletrodo de trabalho pode ser construído de acordo com instruções de Henriques e Fogg ${ }^{14}$. Mistura-se $0,44 \mathrm{~g}$ de epoxi com $0,56 \mathrm{~g}$ de grafite até que fique uma massa completamente homogênea. A cada grama desta mistura, adicionamse 1-2 gotas de HF a $40 \%$ e mistura-se muito bem. (trabalhar na capela pois HF é muito nocivo!). Corta-se a ponta de uma ponteira de $10-100 \mu \mathrm{L}$ de modo que a abertura tenha de 1,5 a 2,0 mm de diâmetro e comprime-se esta ponta sobre a epoxi grafitada que deve subir de 3 a $5 \mathrm{~mm}$ pela ponteira. Firmando a ponta sobre superfície plana e lisa, compacta-se a pasta com o auxílio de um bastão de vidro afilado ao maçarico e inserido pela ponta mais grossa da ponteira. Por este lado, introduz-se um fio de cobre (bem limpo e seco com $\mathrm{HNO}_{3}$ $1+1$ e acetona) que penetra na pasta de 1 a $3 \mathrm{~mm}$, deixando uns $2 \mathrm{~mm}$ de epoxi grafitada além do cobre. Fecha-se a parte de maior diâmetro com epoxi-HF sem grafite (1g de epoxi + 2 gotas de HF) (Figura 5). Deixa-se reticulando por uma noite à temperatura ambiente e mais $2 \mathrm{~h} \mathrm{a} 60^{\circ} \mathrm{C}$. Alisa-se a ponta do eletrodo na seqüência de lixas 400, 600 e 1200. Ao final, poli-se com alumina e aplica-se ultra-som por $5 \mathrm{~min}$ em água. A superfície final do eletrodo deverá ter brilho especular. Se o exame à lupa revelar pequenas crateras na superfície do eletrodo, deve-se aí comprimir mais epoxi grafitada, sem HF, produzindo uma fina camada que se deve endurecer em vapor de $\mathrm{HF}$ por $5 \mathrm{~min}$, seguido de aquecimento por $5 \mathrm{~min}$ a $60^{\circ} \mathrm{C}$. Segue-se polimento em alumina e aplicação de ultra-som. Este ciclo deve ser repetido, se necessário, comprimindo bem a epoxi grafitada sobre a superfície do eletrodo. Um pedaço de papel celofane auxilia nesta aplicação.

Um eletrodo deste tipo forneceu o voltamograma apresentado na figura 6. O sucesso na preparação destes eletrodos está criticamente dependente da qualidade do grafite.

\section{ELETRODO DE PASTA DE GRAFITE}

Um pedaço de $50 \mathrm{~mm}$ de tubo de vidro é cortado e uma de suas pontas polida com lixa e alumina para que fique bem 


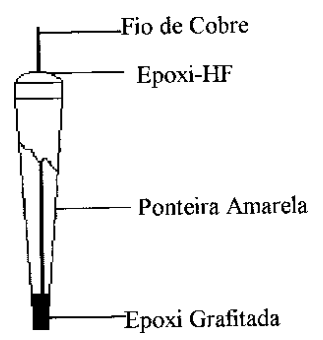

Figura 5. Eletrodo de epoxi grafitada.

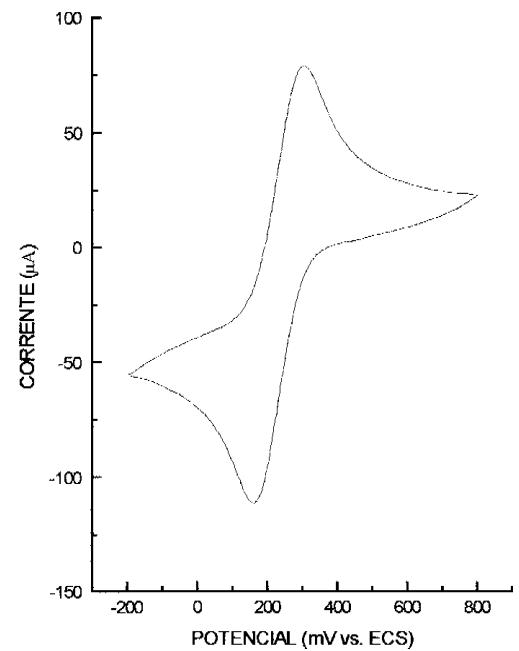

Figura 6. Voltamograma cíclico de uma solução $6 \times 10^{-3} \mathrm{~mol} \mathrm{~L}^{-1}$ de $\mathrm{K}_{3} \mathrm{Fe}(\mathrm{CN})_{6}$. Velocidade de varredura de $50 \mathrm{mVs}^{-1}$. Eletrólito de suporte $\mathrm{KNO}_{3}\left(1 \mathrm{molL}^{-1}\right)$. Eletrodo de epoxi grafitada.

lisa e circularmente uniforme (observe-se sob a lupa). Um pedaço de fio de cobre é colocado em seu interior de modo que haja uma ponta vazia de uns $3 \mathrm{~mm}$ (Figura 7). Fixa-se o fio de cobre com epoxi grafitada-HF na extremidade que ficará vazia e com epoxi-HF sem grafite na extremidade que servirá de contato com o potenciostato. Livra-se a ponta vazia de qualquer porção de epoxi grafitada e $\mathrm{HF}$, deixando o vidro bem limpo. Reticula-se a resina epoxi como foi descrito para o eletrodo de epoxi grafitada e lava-se o eletrodo com água, secando-o em seguida. A cavidade vazia será então preenchida com pasta de grafite $^{12}: 1,5 \mathrm{~g}$ de grafite são misturados a $0,9 \mathrm{~mL}$ de óleo mineral NUJOL até que fique bem homogêneo. Preenche-se a cavidade do eletrodo com esta pasta, evitando-se espaços vazios. Sobre uma folha de papel lisa e limpa, esfrega-se a ponta do eletrodo com movimentos em oito, inicialmente com força e gradualmente de modo mais suave, a fim de obter uma superfície bem lisa. Retira-se qualquer excesso de pasta de grafite antes de usar o eletrodo. A renovação da superfície é feita por remoção escrupulosa da pasta de grafite da ponta, substituindo-a por nova porção. Um eletrodo deste tipo forneceu o voltamograma da figura 8 . Resultados melhores podem ser conseguidos pela diminuição da resistência elétrica do eletrodo, por exemplo, pela inserção de um fio de platina entre cobre e pasta de grafite. Mas isto não será necessário se grafite de boa qualidade for usado na resina e na pasta.

\section{AGRADECIMENTOS}

Ao professor Ademir Neves (UFSC), pelas orientações e materiais para voltametria de complexos em acetonitrila. À CAPES, CNPq E FINEP, pelo apoio financeiro.

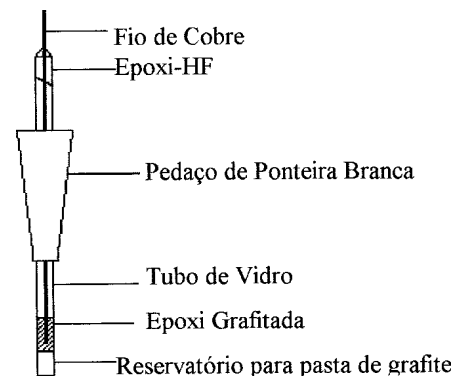

Figura 7. Eletrodo de pasta de grafite.

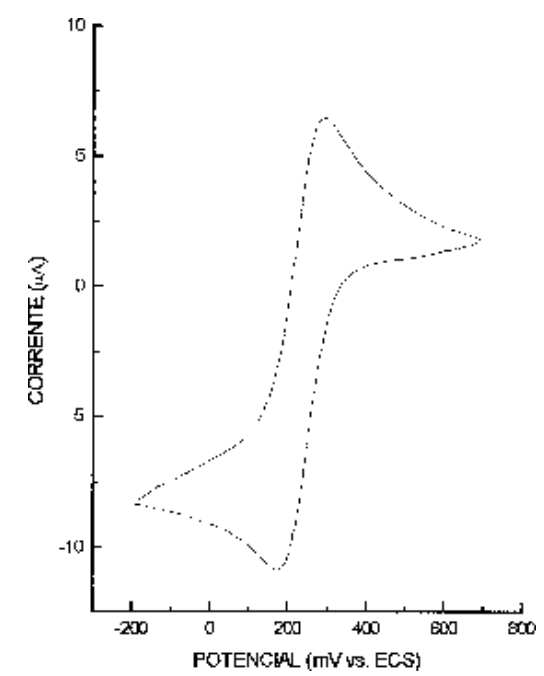

Figura 8. Voltamograma cíclico de uma solução $6 \times 10^{-3} \mathrm{~mol} / \mathrm{L}^{-1}$ de $\mathrm{Ke}_{3} \mathrm{Fe}(\mathrm{CN})_{6}$. Velocidade de varredura de $50 \mathrm{mVs}^{-1}$. Eletrólito de suporte $\mathrm{KNO}_{3}\left(\right.$ lmolL $\left.^{-1}\right)$. Eletrodo de pasta de grafite.

\section{REFERÊNCIAS}

1. Nóbrega, J. A.; Neves, E. A.; Rocha, F. R. P.; Luccas, P. O.; Oliveira, V.; Gouveia. S. T.; Quím. Nova 1996, 19, 684.

2. Lopes, N.; Fugihara, C. S.; Sumodjo, P. T.; Benedetti, A. V.; Quím. Nova 1987, 10, 132.

3. Boodts, J. F. C.; Galli, A. M.; Bottecchia, O. L.; Quím. Nova 1988, 11, 228.

4. Pela, C. A.; Bruçó, J. L.; Stradiotto, N. R.; Quím. Nova 1989, 12, 94.

5. Reis, B. F.; Quím.Nova 1989, 12, 282.

6. Mazo, L. H.; Quím. Nova 1991,14, 87.

7. Gruber, J.; Pardini, V. L.; Viertler, H.; Quím. Nova 1992, $15,83$.

8. Reis, B. F.; Giné, M. F.; Kronka, E. A. M.; Quím. Nova 1992, 15, 231.

9. Li, R. W. C.; Nakamura, M. S.; Gruber, J.; Quím. Nova 1996, 19, 311.

10. Sawyer; Hanemamm; Beebe; Chemistry Experiments for Instrumental Methods; John Wiley \& Sons; New York, 1984.

11. Galster, H.; pH Measurement; VCH; Weiheim, 1991.

12. Adams, R. N.; Electrochemistry at Solid Electrodes; Marcel Dekker, Inc.; New York, 1969.

13. Sawyer, D. T.; Roberts, J. L.; Electrochemistry for Chemists; John Wiley \& Sons; New York, 1974.

14. Henriques, H. P.; Fogg, A. G.; Analyst 1984, 109, 1195.

15. Gagné, R. R.; Koval, C. A.; Lisensky, G. C.; Inorg. Chem. 1980, 19, 2854.

16. Barbour, R.; Glassblowing for Laboratory Technicians; Pergamon Press; Oxford, 1978. 